\title{
Consumer Co-creation: An Opportunity to Humanise the New Product Development Process.
}

\begin{abstract}
A new perspective, that of co-creation, in which consumers are 'active' participants in the design and development of new products, is challenging the traditional model of new product development (NPD). Co-creation provides an opportunity for market researchers to develop a people-centric approach to research thereby humanising the NPD process. Based on the findings from four in-depth case studies within global brand manufacturers in the fast moving consumer goods (FMCG) industry this paper develops a framework for understanding the organisational processes that support consumer co-creation within NPD. Key to co-creation practices are (1) a culture supporting innovation and co-creation (2) a strategy for consumer selection (3) a focus on qualitative research methods and (4)training in business creativity and relationship building skills.
\end{abstract}

Keywords: Consumers, Co-creation process, New product development, Market Research, Brands, Creativity. 


\section{Introduction}

For many organisations, management of the new product development (NPD) process and its associated activities has become an important competitive concern. In a dynamic global marketplace, organisations are searching for new ways to improve their innovation performance. One such way is to adopt an 'open innovation' modus operandi (Chesbrough 2007; Holmes \& Smart, 2009; Dahlander \& Gann 2010), which advocates the use of ideas and knowledge from external sources. This resonates with recent academic thinking on co-creation that suggests that participation in the (NPD) process should now be extended to a wider audience, which includes consumers of the product or service (Roberts et al. 2005; Blazevic \& Lievens 2008; Mahr et al. 2014; Schweitzer et al. 2014 ). Our research suggests that it is here in this new co-creation space that market researchers can extend their skill sets, demonstrate their creativity, and provide organisations with new richer consumer insights to guide the NPD process.

Writing in IJMR, Roberts and Adams (2011) highlighted co-creation as one of the challenges confronting marketers. This approach is gaining in popularity in a number of industries such as telecommunications, car manufacturing and fast moving consumer goods (FMCG). Yet, traditionally NPD studies have taken a 'passive' stance to consumer involvement. Co-creation logic offers a new way of thinking about marketing and NPD specifically, and this requires an understanding of co-creation practices and how to manage the process to deliver successful NPD outcomes. Although a number of co-creation studies are emerging which recognise the potential for consumer co-creation, a systematic literature review by Perks and Roberts (2013) found a lack of empirically grounded frameworks to guide management practice and research. Most studies have taken a conceptual stance (Greer \& Lei 2012), or have focused on the use of technology as a conduit for consumer interaction, e.g. Sawhney et al. (2005), and Franke et al. (2008). A focus on 'active', face-to face interaction and collaboration with consumers throughout the whole of the NPD process is rare. 
Responding to this research problem is important because understanding the co-creation process may reduce risks associated with NPD by helping organisations develop products that provide better value for the consumer and the firm (Hoyer et al. 2010; Cook 2008). In an age when many organisations are struggling with a deluge of data we argue that co-creation can provide a real insight into consumers and an opportunity to humanise the data. Cocreation has been assigned a range of different meanings by researchers (Nysveen \& Pedersen 2014), but in the context of NPD it is defined as "a collaborative NPD activity in which customers actively contribute and/or select the content of a new product offering," (O’Hern \& Rindfleisch 2010, p86). This paper explores the collaborative practice of direct, face-to-face consumer involvement in the NPD process. It examines the process of 'working with' consumers from the ideation stage to new product launch. The contribution of this paper is to add understanding of co-creation practices and the processes that support a co-creation capability for NPD. It does so by exploring the NPD and co-creation processes within global brand manufacturers operating in FMCG markets. We provide a model of the co-creation process for NPD, which is informed by field research, and encapsulates the strategic and tactical decisions and activities that are taking place. Through the process of constructing our model and explaining the constituent parts, we demonstrate how market researchers can support and help managers develop co-creation activities for NPD.

\section{The co-creation landscape}

In recent years research co-creation research has advanced mainly within two interconnected streams of literature: marketing and innovation. In the marketing literature interest in co-creation has been sparked considerably by the work of Vargo and Lusch (2004) who place co-creation at the centre of the service-dominant (S.D) logic. Central to S.D logic is the concept of co-creating with customers and partners and the sharing of skills and knowledge in creating a competitive advantage through jointly delivering value. This requires organisations to have the ability to collaborate with and 'learn from' consumers. From this perspective consumers are no longer perceived to be passive participants in the marketing and NPD process. As such, it represents a shift in thinking and the focus of marketing and NPD to 'with and among' customers rather than 'to customers' (Vargo \& Lusch 2004). Under S.D 
logic customer value is created through collaboration, the development of relationships, and the sharing of skills and knowledge (Aitken, Ballantyne, Osbourne \& Williams 2006). However, according to Maklan et al. (2008), the new status of customers as co-creators of value presents a formidable challenge to market researchers who are often detached from the subject of study. Maklan et al. (2008) highlight the need for researchers to adopt more collaborative approaches to research with a focus on 'usefulness' as opposed to 'validity'.

In the innovation literature, researchers have focused on involving customers in the NPD process in order to better understand their needs and subsequently to design new products and services that fit those needs (Mahr et al. 2014; Hoyer et al. 2010). Co-creation has emerged from shifts in paradigm-thinking from firm to user-centred innovation. Seminal work by von-Hippel (1986) demonstrated that sources of innovation are often external to the firm and introduced the customer active paradigm (CAP) of innovation whereby customers are active participants in generating new ideas for NPD. Von-Hippel's research identified the importance of working with 'lead users', those whose needs are ahead of market trends relative to the majority of users, to deliver improved productivity in NPD. However, von-Hippel's research on lead users was limited to a carefully selected, knowledgeable and elite group of customers, and their co-development activities in industrial markets. More recently, Matthing et al. (2006) have extended the concept of 'lead userness' into consumer markets, and have suggested that 'lead users' would have similar characteristics to those in industrial markets e.g. well-developed needs and willingness to participate in fulfilling those needs. In consumer markets, it was also found that 'opinion formers' have characteristics that correlate with lead userness. Thus, consumers have the potential to become a source of knowledge, which is central to the innovation process, and an important resource for the organisation. Co-creation is considered to be an avenue whereby firms develop relationships, and interact with customers (Perks, et al., 2012); thus gaining access to new knowledge (Roser et al, 2013), that is required for innovation.

\section{Technology versus face-to-face co-creation}


Web-based technology has helped shape the co-creation landscape by enabling companies to carry out co-creation activities with a wide range of customers at relatively low cost (Evans \& Wolf 2005; Hoyer et al. 2010; Sawhney et al. 2005). Some studies have focused on customer knowledge, and the use of technology to gather insights through different communication channels and from different communities (Cui \& Wu 2016; Mahr et al. 2014). Other studies have focused on the technology itself and how the provision of user toolkits (Franke \& Piller 2004; von-Hippel \& Katz 2002) and co-design platforms (Berger \& Piller 2003) can empower customers to become an active part of the NPD process. The effectiveness of involving customers in the NPD process has been shown to vary (Chang \& Taylor 2016) and there has been some debate as to the advantages and drawbacks of using technology-based methods such as the web or user toolkits; versus more traditional face-to-face methods such as interviews or focus groups (Mahr et al. 2014). Technology-based methods can have a wide reach and allow the participation of many customers from different geographical areas at a low cost, although response rate can be low and participants can drop out of the process easily (Dahan \& Hauser 2002). Face-to-face methods allow for a more comprehensive understanding of complex non-verbal cues such as body-language (Blazevic \& Lievens 2008), rich discussions which can reduce misunderstanding, and the transfer of tacit-knowledge which is hard to capture in writing (Mahr et al. 2014), but are more expensive than technology-based methods (Hoyer et al. 2010). Both technology-based and face-to-face methods could be used to address the weaknesses of the other. However, research on direct, face-to-face consumer co-creation in NPD and the mechanisms that support this process remains in its infancy (Cui \& Wu 2016).

\section{Creativity and ideation}

Dahlsten (2004) attempted to address the paucity of research on direct, face-to-face consumer co-creation in NPD at Volvo cars. Using an experimental approach, consumers became part of the NPD team and were involved throughout the entire NPD process. The ability to attain generative knowledge and stimulate organisational learning and creativity were considered to be the advantages of adopting a co-creation approach. This approach was also supported by the use of traditional market research activities. A study by Kristensson et al. (2004) found 
that ordinary consumers were able to generate unique and valuable ideas that were more creative and original than those produced by the professional development team. Roberts et al. (2005) also found that the inclusion of consumers in the team challenged managers forcing them to look for more creative and less obvious solutions.

The use of creative problem solving tools, (Synectics), helped to facilitate the co-creation process and led to more creative outcome (Roberts et al. 2005). Consumers do not necessarily need to possess domain skills when cocreating but need to express a certain level of interest in the task if their contribution is to be of value (Fuller et al. 2012).

\section{Dialogue and social interaction}

A steady flow of ideas is needed to support the NPD process and creativity is needed to generate, select and put good ideas into practice. Ideas, which feed the innovation process, are derived from dialogue and social interaction with customers (Flint 2006). Dialogue is seen as one of the building blocks of interaction (Prahalad \& Ramaswamy 2002) and is a process of listening and learning, which can lead to the co-creation and sharing of knowledge. According to Ballantyne and Varey (2006) interaction is crucial for collaboration and for relationships. Thus, interplay among managers responsible for innovation and consumers' is important and enhances knowledge and the creative process. Dahlsten's (2004) study at Volvo reports how female consumer involvement and interaction in the project was managed in a more subtle way, 'tacit design by customer presence', than is normally suggested in the literature. Hence, consumer involvement can be seen as a socialization process where tacit knowledge was co-opted by the organization in an attempt to understand the consumer and contextualize the product development process.

The literature suggests that co-creation in NPD is beneficial to both the consumers and the firm (Gemser \&Perks 2015; Hoyer et al. 2010), and will provide the opportunity to generate and co-create knowledge. Directly involving consumers in the process leads to a better fulfilment of their needs (von-Hippel 2001; Kristensson et al. 2004). It also allows needs, which are 'sticky' and difficult to articulate to be uncovered (von-Hippel 2001; 
Dahlsten 2004). Involving the consumer from the earliest stages in the co-creation of value is beneficial in that it reduces the risk that the consumer will reject the end product (Prahalad \& Ramaswamy 2004).

In this regard traditional research methods have often been found wanting (Thomke \& von-Hippel 2002).

Additionally, organisations are now demanding more from their research agencies (Smith 2007). They want a more fine-grained understanding of the complex, social and cultural environment in which consumers reside. Cocreating with consumers provides such an opportunity as it requires 'working with' and 'learning from' consumers (Roberts \& Palmer, 2012). Cui \& Wu, (2016), describe three forms of customer involvement, customers as an information source, which is akin to traditional methods of research, customers as co-developers where customers develop products with the NPD team, and customers as innovators where customers design their own products. Flint (2006) asserts that managers and researchers must be willing to adopt alternative perspectives of the consumer and utilise different market research methodologies to study them. In particular, he advocates the use of qualitative techniques and participant observation to observe social interactions; an idea similar to that of Empathic Design proposed earlier by Leonard and Rayport (1997).

\section{RESEARCH METHODOLOGY}

An exploratory, multiple, holistic case study design was adopted. The case study method allows for 'multiple sources' of evidence, and can facilitate in-depth understanding of emerging and complex phenomena, such as cocreation without removing it from its social context and real life setting (Yin 2002). Companies were selected on the basis of their co-creation activities, investment in market research, brands and NPD process. The case study sample, list of informants and data availability are illustrated in Table1. The co-creation projects were all classified as incremental and involved the development of a new household product, a new snack-food, a new alcoholic beverage, and a new confectionery product. 
The principal method of field research was interviews, which was supplemented with internal documents pertaining to product and brand strategy, the NPD process, and market research reports. Semi-structured interviews were used to guide the process. This enabled respondents to explore and describe their role in the cocreation process. In line with good practice, a flexible topic guide was informed by the literature on co-creation marketing, innovation management and market research. This was used only as a rough guide as advocated by (Story et al. 2009), and was refined as interesting themes emerged throughout the process. The respondents were asked to narrate their role in the NPD process and were questioned in-depth with regard to consumer involvement and interaction. The focus of the analysis was on uncovering actions taken by managers to co-create with consumers in the NPD process, and the development of the conditions and necessary skills for co-creation to take place. The emerging insights were checked on an ongoing basis with the participants, and the results were presented at a workshop with representatives from each case organisation. Through a process of comparing the cases and combining the data an overall meta-case of the practice of the NPD co-creation process was constructed and emerging themes were uncovered.

INSERT TABLE 1 HERE 


\section{FINDINGS}

The findings represent a combined overview and synthesis of the four case studies and NPD projects.

Figure 1, provides a visual representation of the co-creation process and summarises the key common organisational issues, activities and decisions. Pervasive throughout the model are common themes found in the literature around creativity, collaboration, dialogue and socialization. Each element is discussed in turn and data is provided in the form of exemplar quotations within the text.

\section{INSERT FIGURE 1 HERE}

\section{Co-creation decisions}

A number of decisions about the type of activities that should take place, what type of consumers should be involved, and how the process could be facilitated were made. Within each project two main approaches to cocreation activities were apparent; these were co-creation or co-development groups, and consumer partnering.

\section{Types of activities}

\section{Co-development groups:}

This was the most common term used for the group activities consisting of managers working on projects with a variety of different consumers Managers and consumers collaborated on project related issues such as societal trend development, idea generation, concept development and selection, product testing and the marketing communications for product launch. When examining the different stages of the NPD process it was apparent that there was a greater use and emphasis of this approach at the ideation and concept development stage, which is often referred to as the 'fuzzy-front' of NPD. This is one of the most critical stages of the NPD process, where ideas are spawned, chosen and refined (Van den Ende \& Frederiksen, 2015). There was consensus amongst all the managers that that the front end of the process is becoming more important in terms of how it is managed and how latent consumer needs are captured. For example it was stated that: 
"The early ideation stage sets the scene for the rest of the project so spending time and getting this right was crucial. The outcome of this project is not just to develop a new product or brand; we are also looking to develop a new product pipeline, which will feed into future NPD projects."

(B8) Innovation Strategist

In the early stages of the project a lot of activities revolved around the exploration of social trends and their implications for NPD. Activities took the form of extended group meetings and intensive workshops held at regular intervals, similar to those reported by Dahlsten (2004) and Cui \& Wu (2016) where consumers helped 'codevelop' the product or service. Describing the process of group co-development, one manager stated:

"The consumers basically developed the ideas with us. We would split into groups and develop the concepts and work on the ideas that we all liked best. It was really high energy, there was a lot of debate and it was very interactive. At the end of the process it was quite amusing watching consumers getting up and presenting concepts that they had been working on and had improved. We all had to vote for the ones that we liked the best."

(D18) Innovation Planner

In some instances consumers also worked together in groups whilst managers acted as observers. The observers gathered ideas and later refined the consumers' concepts. The refined product concepts were then presented back to the consumer groups for further assessment. A manager described the process as:

"Creating a goldfish bowl of consumers; we used the ideas and concepts that the consumers help to generate as a form of stimulus. We combined the ideas and concepts and then further developed and refined them. We then started to build in some commercial feasibility. "

(A3) Product Research Manager 
Unlike the 'lead user' process, consumers worked on behalf of the organisation and not on solutions to their own problems. As suggested by Prahalad and Ramaswamy (2003) the consumer is seen as a partner and source of competence for the organisation that can enhance the innovation process. In consumer co-creation, the focus of the interaction is on the co-creation of knowledge, obtaining knowledge 'from' and 'with' consumers It was explained that:

"By bringing the consumer into the team as a co-developer we are trying to enrich our knowledge bank. It is important to increase diversity in our development and marketing teams and add some new perspectives."

(C14) Marketing Manager

Companies A and C still regarded this process as a trial, but companies B and D have fully adopted this approach. There were limits to co-development, e.g. in the development stages of, which required technical and production expertise and in the business development, which was considered to be too complex and sensitive.

\section{Consumer partners:}

The second approach to co-creation took the form of consumer partnering. This involved individual managers forming a partnership with a consumer who they would meet at frequent intervals. The terms 'marketing mums' and 'consumer buddy' were frequently used to describe the consumer partner and the term 'buddy' reflected the informal nature of the relationship. These meetings were unstructured and were held in a variety of locations such as the supermarket, the school run, the workplace, and sports centres. This 'hanging out' process (Agar 1996) enabled the managers to develop a relationship and build up rapport with their buddy. The aim of the meetings was to gain a better understanding of consumer needs and contexts of use by exploring the consumer buddy's wider social and cultural environment, generating insights for the product innovation process. 
"The idea was that the managers would meet their consumer buddies and then we would get back together as a team and discuss the findings. The idea was that if we could get the managers in front of consumers, one on one, in a real life situation, it is much richer information, which we could use both in this and other projects."

(D21) Market Research Consultant

This approach was facilitated by the marketing researchers and consultants. By helping managers experience the world through the eyes of the consumer buddy, they were able to develop an 'empathic understanding', or 'visceral feel' (Dougherty 1992; Roberts \& Palmer 2012) for what is important in consumers lives and for what they are looking for in terms of product innovation.

Developing a dialogue with the consumer buddy was an interactive process of learning together. It helped to provide different perspectives from those of the NPD teams and to create new knowledge for use in the NPD process. It was explained:

"We would meet with our consumer buddies and then after each session we would meet with our team and we would discuss analyse the findings. Sometimes it took us some time to realise the importance, or recognise the insight."

(D20) Brand Manager

Building a greater awareness of the social, emotional and cultural contexts that defines consumer experiences was seen as a stepping stone in the co-creation process, and this knowledge could be used at every stage of the project. It was explained as follows: 
“Not only do we need to understand a target market that we are not part of, e.g. what it's like to be eighteen and on the club circuit but we need to understand their experiences, culture and communities. These people are connected and informed in ways that would have been unimaginable in the past, so we need to explore new approaches to innovation and to connecting and developing with them."

(B10) Innovation Consultant

Company D felt that some of their innovation and marketing team were too disconnected from their target markets in terms of their educational and social background and their Board members were even further removed. To try and remedy this problem they presented videos of their consumer partner visits and co-creation activities to the Board.

\section{Choice of Consumer}

Studies, e.g. Gruner and Homburg (2000) have reported improved NPD success when incorporating lead users into the development team. However, a major challenge was the identification of consumers who were willing and able to participate to the process. In the context of consumer markets, typified by large numbers of users, the respondents felt that identifying lead users remains problematic. Thus, various other approaches to selecting consumers to work with were used, such as the identification of consumer creativity attributes and in companies B and D personality traits e.g. 'innovativeness' (Rogers 1962) were used. Consumers selected to help co-create new products were more likely to be identified as 'early adopters', or 'pioneers'. A consultant commented:

"We select consumers to work with us that we consider being ahead in adoption, connected socially and electronically, and travel extensively. We also looked to work with consumers that are vocal and opinionated and are respected by their peers."

(D22) Marketing/Innovation Consultant 
Amabile (1998) has shown that creativity is enhanced through co-worker diversity and integrating people with different cognitive styles. Therefore, consumers from a diverse range of backgrounds rather than the customary target market consumers were chosen:

“We chose consumers for their ability to contribute 'vocally' and not to feel intimidated working alongside NPD professionals, it didn't matter that there weren't necessarily our target market."

(B7) Brand Planning Manager

But later in the development process a number of more 'conservative' consumers were also incorporated into the teams. Individuals that are predisposed to purchase new products earlier were not necessarily representative of the target market. It was stated that:

"In order to be able to identify any resistance to the new concepts by the target market we felt it necessary to involve some consumers that were more representative of the mass market."

(D22)Marketing/Innovation Consultant

The marketing research agencies played a central role in helping to identify consumers to take part in co-creation activities. A marketing research agency sometimes chose consumers for their expertise in various fields that were totally unrelated to the FMCG market, such as actors and therapists and architects. These people were termed as 'unrelated inspirers' by the Innovation Manager in company D. When selecting consumers to work with, their motivations for wanting to take part also had to be taken into account. Unlike business to business markets where the aim of collaborative relationships is mutual gain for both parties, the consumers' motivations for taking part were more complex. It was generally acknowledged that consumers' motivations included financial gain, e.g. payment for their time, acknowledgement of their expertise, the need for socialisation, and satisfaction at the outcome of the project. This resonates with the work of Franke and Schreier (2010), and Roberts et al. (2014) who found that consumers pursue intrinsic psychological benefits through co-creation activities. 


\section{Facilitating the co-creation process}

Although the companies are well resourced and open to the possibilities that co-creation can bring forth, this is not enough for the process to come about. Marketing research agencies played a key role in helping managers understand the tools and techniques to facilitate co-creation. These included the use of visualisation, storytelling, analogy and creative problem solving (or problem framing). It was explained that the use of problem framing in the early stages of the projects was designed to provoke in-depth questioning amongst the participants and to encourage them to reject the typical or obvious solutions. The creative problem solving techniques ranged from the use of simple brainstorming to a more sophisticated Synectics problem solving process, as outlined in Roberts et al. (2005). The Synectics approach to design and NPD advocates the use of personal, fantasy and symbolic analogies.

Co-creation activities appeared to run counter to successful NPD practices with an internal focus on planning and control, and reliance on agencies to act as a conduit to the consumer. Thus, a number of different training and development initiatives were put in place, often introduced and facilitated by the research agencies. The main aim of the training was to enhance the managers' skills in collaboration and relationship building. Another key aim of the training was to make managers more comfortable with working with different people, and to promote creativity and divergent thinking:

"We wanted the team to work with different people. We wanted them to become observant to notice things about people that they wouldn't usually come across. Everyone here is very similar; we have all been to University, hold managerial positions and have similar salaries. It is easy to become blinded."

(B6) Marketing Manager

The process of working with different people, with consumers is similar to what Leonard and Sensiper (1998), term 'creative abrasion' where ideas from diverse viewpoints are channelled into the NPD process. It also helped 
managers to challenge the conventional way of doing things in the organization. It could be seen from the data that co-creation is emerging as a creative and social process that entails making connections and exchanges with people and recognising the creativity inherent in individuals. It was stated that:

"I think companies are beginning to realise that the spark and creativity comes from connecting. And therefore you need to be as open as you can be and connecting with as many diverse sources of ideas as possible. Exactly how one does that, and how one manages the process, and what does one keep secret, and how you create fruitful connections with consumers and so on, these are the new agenda."

(A1) Marketing Director

Marketing research agencies provided managers with some basic training in ethnographically orientated research methods. Rather than just the market research agency going through the process, managers also immersed themselves in the consumers' daily life and learnt to record, interpret and disseminate their findings to the project team. The focus of the training was not on rigor in research methodology but on the interpretation of their findings to develop insights. The ability to capture, manage and communicate knowledge that is co-produced was a core activity and the findings were represented in creative ways which included visual story boards to represent the societal trends, storytelling, the use of metaphor, and videos.

\section{Innovation culture and climate}

The findings demonstrate the importance of developing quality relationships and dialogue with consumers. This interactive process of learning together was supported by senior managers. Senior managers play a significant role in shaping organizational culture and in supporting new initiatives such as co-creation. Although each of the case organisations had their own unique style and culture, there were common positive aspects of their culture and climate that supported co-creation. In particular, the ability to 'have fun', play and experiment with different approaches to co-creation, and a tolerance of what McLaughlin et al. (2008) term 'fast failure', which is a mandate to learn from collaboration with consumers, were all important. It was stated that: 
"We were given the freedom to experiment with different approaches to involving the consumer in the NPD process, to co-creation, but it's still evolving. We had to look at what best suited the needs of the project and we had to learn fast from any attempts at collaboration with consumers".

(D18) Innovation Planner

"Although we have been given the freedom to experiment we are still a very numbers driven organisation.

We are at a stage where we have been given the endorsement to play around with NPD but if we don't deliver in the next 6-9 months people will say forget it."

(B6) Marketing Manager

There was further evidence of supporters, or 'champions', of co-creation. These supporters were both internal and external (e.g. the market research agencies), and they were instrumental in driving the projects and in communicating any successes from this approach throughout the organisation.

"We are fortunate the creation of the innovation group means that we are not constrained by the brands or the needs of the factory. The head of the group and the people working in it act as kinds of champions for this and other projects. At times they can become almost evangelical!”

(D19)Innovation Project Manager

Similarly, Company A has senior level managers with responsibility for research and development that can support new project initiatives:

"Roger is lucky, because of his seniority he has the license to experiment with things such as co-creation and blue sky type thinking. He has access to senior people throughout the globe, so he can really help and get people behind a project."

(A3) Products Research Manager 
As this approach is still in its infancy managers needed the freedom to experiment with approaches to co-creation that best suit their needs and have a mandate to learn from any attempts at collaboration with consumers. This learning process allowed behavioural routines, which are important determinants of successful innovation (Nonaka 1991) to develop around the co-creation process.

\section{DISCUSSION AND IMPLICATIONS}

A generation of empowered consumers that are more willing to learn, share, learn and note their experiences is emerging. Consumers are demanding more opportunities for creative involvement and engagement, which cocreation can provide (Medeiros \& Needham 2008; Gemser \& Perks 2015), but adopting co-creation signifies a departure from the traditional, internally focused model of NPD. It requires an understanding and tolerance of the need for 'openness', and requires a commitment in terms of time, resources and the development of new capabilities. It requires organizations to adopt a long-term perspective, to push the boundaries of their current operating practices, and to learn through doing. We argue that the market research community is well-positioned to facilitate this transition and to help firms develop a co-creation strategy.

From a top level strategic perspective, co-creation activities are contingent upon the level of involvement (passive or active) that the organization is willing and able to adopt, and also upon the purpose of being involved.

Developing an NPD strategy for co-creation is also important that can answer the following questions: what is the purpose and role of the consumer in the process? Are consumers expected to provide or stimulate ideas? Are they expected to actively participate and co-create in the development of new ideas and concepts? Also, which projects should they be involved in? And at what stage of the NPD process should they be involved. The findings lend support to Chang and Taylor's (2016) view that co-creating with consumers in the early stages of NPD provides a wealth of information from diverse perspectives and can help the firm to avoid wasting resources on low value projects. The companies involved in this study felt that co-creation was important for developing new products 
rather than for incremental improvements to existing products. Similar to Chang and Taylor's (2016) findings, it was implied that the value of co-creation diminishes during the more technical development stage but increases again at commercialisation where consumers can provide useful feedback on market positioning and product use.

Decisions need to be made about the type and length of engagement with consumers. For instance codevelopment workshops are episodic with different consumers being brought in and out of the process. In contrast, a consumer buddying system is an ongoing process of relationship development. Here, as suggested by Ballantyne and Vary (2006) what is important is the quality of the relationship. When asking managers if they would approach co-creation activities differently in the future, they suggested that careful selection of the consumer buddy was important, in addition to regular communication and activities. However, it was also felt that there was a need to better explain the value of this approach, which sometimes appeared to provide ambiguous findings. It was felt that in the future, the NPD team would try to extend participation in co-creation activities to a wider audience within the organization, and to sell the benefits of this approach in order to reduce any resistance to this novel approach.

Thus, when developing the NPD strategy clear goals and objectives need to be set and top level management support is needed. Decisions need to be made on the type of consumer to work with and this again will depend upon the NPD strategy and what the firm is trying to achieve. Our study suggests that there is an opportunity for market researchers to offer their skills and knowledge to provide a more holistic view and service to their clients in terms of strategy development, the selection of consumers and the management and facilitation of co-creation activities. As co-creation becomes more prevalent, managers will need to utilise their current knowledge of best practice in managing the NPD process and traditional modes of market research, in addition to developing collaborative relationship building skills. Empowering both managers and consumers to co-create and cultivating an environment for creativity to flourish were important parts of the training and development initiatives. 
The literature review highlighted the fundamental aspects that support co-creation: dialogue, creativity, collaboration and relationships. This study provides empirical evidence of how these elements are operationalised and how co-creation occurs in practice. The framework presented in Figure 1 is grounded in field-based research within global brand organisations. It brings together the common strategic and tactical decisions that have to be made when adopting a co-creation approach to NPD and in developing a co-creation capability. In line with SD logic it demonstrates how consumers can become partners and share skills and knowledge to create value through NPD. It sheds light on the practices of co-creation and how firms can 'learn from' consumers. In particular it supports the work of Amabile (1998) and others on the importance of diversity to aid creativity and the generation of new product ideas. Co-creation both helps to diversify thinking within the NPD team by involving consumers from different backgrounds and by challenging the team to learn new ways of doing things.

This study could help marketing researchers and their client organisations by demonstrating the practice of co-creation and showing its value throughout the NPD process. Figure 1 provides marketing researchers with an overview of how co-creation is implemented in large firms and could be used as a framework on which to base future NPD processes and strategic decisions. It also shows the importance of using a qualitative approach to understand the complexity of co-creation and to provide more powerful insights based on human experience. Humanising the process we argue, is particularly important during a time when reliance on big data and technology is becoming more prevalent. It is still vital to gain an in-depth understanding of the human behaviour and aspects that influence NPD and not become overzealous about technology. It shows that using a qualitative approach can help us gain a comprehensive understanding of the complex human interactions involved in the co-creation process. 
Future research could examine the effectiveness of technology-based and face-to-face co-creation methods during different stages of the NPD process and across different industries. Only by fine-tuning a combination of the two methods can companies hope to extract the maximum value from their cocreation activities and strike a balance between cost, reach, and depth of understanding. 


\section{References}

Agar, M. (1996) The Professional Stranger, Academic Press, London.

Amabile, T.M. (1998) How to Kill Creativity. Harvard Business Review, 76, 77-87.

Ballantyne, D., \& Varey, R. J. (2006) Creating value-in-use through marketing interaction: the exchange logic of relating, communicating and knowing. Marketing Theory, 6(3), 335-348.

Berger, C. \& Piller, F. (2003) Customers as Co-Designers. IEE Manufacturing Engineer, 42-45.

Blazevic, V. \& Lievens, A. (2008) Managing Innovation Through Customer Co- produced Knowledge in Electronic Services: An Exploratory Study. Journal of the Academy of Marketing Science, 36, 138-151.

Chang, W., \& Taylor, S. A. (2016) The effectiveness of customer participation in new product development: a meta-analysis. Journal of Marketing, 80(1), 47-64.

Cui, A. S., \& Wu, F. (2016) Utilizing customer knowledge in innovation: antecedents and impact of customer involvement on new product performance. Journal of the Academy of Marketing Science, 44(4), 516-538.

Dahan, E., \& Hauser, J. R. (2002) The virtual customer. Journal of Product Innovation Management, 19(5), 332-353.

Chesbrough, H. (2007) Why Companies Should Have Open Business Models. MIT Sloan Management Review, 48, 22-28.

Cui, A. S., \& Wu, F. (2016) Utilizing customer knowledge in innovation: antecedents and impact of customer involvement on new product performance. Journal of the Academy of Marketing Science, 44(4), 516-538 
Cook, S. (2008) The contribution revolution: Letting volunteers build your business. Harvard business review, 86, 60-69.

Dahlander, L., \& Gann, D. (2010) How open is innovation? Research Policy, 39, 699-709.

Dahlsten, F. (2004) Hollywood Wives Revisited: A Study of Customer Involvement in the XC90 Project at Volvo Cars. European Journal of Innovation Management, 7, 141-149.

Dougherty, D. (1992) Interpretive barriers to successful product innovation in large firms. Organization science, 3(2), 179-202.

Flint, D. J. (2006) Innovation, symbolic interaction and customer valuing: thoughts stemming from a servicedominant logic of marketing. Marketing Theory, 6(3), 349-362.

Franke, N. \& Piller, F. (2004) Toolkits for User Involvement and Design: The Case of the Watch Market. Journal of Product Innovation Management, 21, 401-415.

Franke, N., Keinz, P., \& Schreier, M. (2008) Complementing Mass Customization Toolkits with User Communities: How Peer Input Improves Customer Self-Design*. Journal of product innovation management, 25, $546-559$.

Franke, N., \& Schreier, M. (2010) Why Customers Value Self-Designed Products: The Importance of Process Effort and Enjoyment*. Journal of Product Innovation Management, 27, 1020-1031.

Füller, J., Matzler, K., Hutter, K., \& Hautz, J. (2012) Consumers' creative talent: Which characteristics qualify consumers for open innovation projects? An exploration of asymmetrical effects. Creativity and Innovation Management, 21, 247-262

Gemser, G., \& Perks, H. (2015) Co-Creation with Customers: An Evolving Innovation Research Field. Journal of Product Innovation Management, 32, 660-665. 
Greer, C. R., \& Lei, D. (2012) Collaborative innovation with customers: a review of the literature and suggestions for future research*. International Journal of Management Reviews, 14(1), 63-84.

Gruner, K. \& Homburg, C. (2000) Does Customer Interaction Enhance New Product Success? Journal of Business Research, 49, 1-14.

Holmes, S., \& Smart, P. (2009) Exploring open innovation practice in firm-nonprofit engagements: a corporate social responsibility perspective. $R \&$ D Management, 39(4), 394-409.

Kristensson, P., Gustafsson, A. \& Archer, T. (2004) Harnessing the Creative Potential Among Users. Journal of Product Innovation Management, 21, 4-14.

Leonard, D., \& Rayport, J. F. (1997) Spark innovation through empathic design. Harvard business review, 75, 102-115.

Leonard, D.A. \& Sensiper, S. (1998) The Role of Tacit Knowledge in Group Innovation. California Management Review, 40, 112-133

Mahr, D., Lievens, A. \& Blazevic, V. (2014) The Value of Customer Cocreated Knowledge during the Innovation Process. Journal of Product Innovation Management, 31, 599-615.

Maklan, S., Knox, S., \& Ryals, L. (2008) New trends in innovation and customer relationship management: a challenge for market researchers. International Journal of Market Research, 50(2), 221-239.

McLaughlin, P., Bessant, J., \& Smart, P. (2008) Developing an organisation culture to facilitate radical innovation. International Journal of Technology Management, 44, 298-323.

Medeiros, A.C.M \& Needham, A. (2008) The Co-creation Revolution. Proceedings of the Innovate Conference, Copenhagen, June 2008, [CD ROM].

Matthing, J., Kristensson, P. \& Gustafsson, A. (2006) Developing Successful Technology Based Services: The Issue of Identifying and Involving Innovative Users. Journal of Services Marketing, 20, 288-297.

Nonaka, I. (1991) The knowledge-creating company. Harvard business review, 69, 96-104. 
Nysveen, H., \& Pedersen, P. E. (2014) Influences of co-creation on brand experience The role of brand engagement. International Journal of Market Research, 56(6), 807-832.

O’hern, M., \& Rindfleisch, A. (2010) Customer co-creation. Review of marketing research, 84-116.

Perks, H., \& Roberts, D. (2013) A review of longitudinal research in the product innovation field, with discussion of utility and conduct of sequence analysis. Journal of Product Innovation Management, 30(6), 1099-1111.

Prahalad, C.K. \& Ramaswamy, V. (2004) Co-Creation Experiences: The Next Practice in Value Creation. Journal of Interactive Marketing, 18, pp. 5-14.

Roberts, D. L., Walker, D. \& Baker, S. (2005) Can We Learn Together? Co-creating with Consumers. International Journal of Market Research. 47,407-427.

Roberts, D.L., \& Adams, R. (2011) Agenda development for marketing research. International Journal of Market Research, 52(3).

Roberts, D. L., \& Palmer, R. (2012) Developing a visceral market learning capability for new product development. International Journal of Market Research, 54(2), 199-220.

Roberts, D.L, Hughes, M., \& Kertbo, K. (2014) Exploring consumers' motivations to engage in innovation through co-creation activities. European Journal of Marketing, 48, 147-169.

Rogers, E.M. (1962) Diffusion of Innovation, Free Press, New York.

Sawhney, M., Verona, G., \& Prandelli, E. (2005) Collaborating to create: The Internet as a platform for customer engagement in product innovation. Journal of interactive marketing, 19(4), 4-17.

Schweitzer, F., Gassmann, O., \& Rau, C. (2014) Lessons from Ideation: Where Does User Involvement Lead Us? Creativity and Innovation Management, 23, 155-167.

Smith, D. V. (2007) Creating Maximum Value for the Client: Developing a New Strategic Role for Market Researchers. Market Research Best Practice, 30, 3-23.

Thomke, S., \& von Hippel, E. (2002) Innovators. Harvard business review, 80(4), 74-81. 
Vargo, S. \& Lusch, R. (2004) Evolving to a New Dominant Logic for Marketing. Journal of Marketing, 68, 1-17.

Ende, J., Frederiksen, L., \& Prencipe, A. (2015) The front end of innovation: Organizing search for ideas. Journal of Product Innovation Management, 32(4), 482-487.

von-Hippel, E. (1986) Lead Users: A Source of Novel Product Concepts. Management Science, 32, 791-805.

von-Hippel, E. (2001) Perspective: User Toolkits for Innovation. Journal of Product Innovation Management 18, 247-257.

von-Hippel, E. \& Katz, R. (2002) Shifting innovation to users via toolkits. Management Science, 47, 821-833.

Yin, R.K. (2002) Case Study Research: Design and Methods ,2 ${ }^{\text {nd }}$ edn. Sage, London. 
Table 1. Overview of Sample and Data Availability

\begin{tabular}{|c|c|c|c|c|c|}
\hline Companies & Industry/ Parent Company & $\begin{array}{l}\text { Informant ( Interviewee ID } \\
\text { Number) }\end{array}$ & $\begin{array}{l}\text { Age } \\
\text { Range }\end{array}$ & $\begin{array}{l}\text { Observation of co- } \\
\text { creation activities }\end{array}$ & $\begin{array}{l}\text { Internal project } \\
\text { documents } \\
\text { inspected }\end{array}$ \\
\hline $\begin{array}{l}\text { Case A. } \\
\text { Location multi-sites in Western } \\
\text { Europe. } \\
\text { Development of new Household } \\
\text { Detergent Brand }\end{array}$ & $\begin{array}{l}\text { Global brand leader in household and personal care. } \\
138,000 \text { Employees } \\
\text { Operates in } 80 \text { countries } \\
\text { Approx. turnover } \$ 76 \text { billion } \\
\text { Innovation ethos: connect \& collaborate }\end{array}$ & $\begin{array}{l}\text { Marketing Director (1) } \\
\text { Research Fellow R\&D (2) } \\
\text { Products Research Manager (3) } \\
\text { Market Research Manager (4) } \\
\text { Technology Scout (5) }\end{array}$ & $\begin{array}{l}45-50 \\
50-55 \\
30-35 \\
30-35 \\
35-40\end{array}$ & Yes & $\begin{array}{c}\text { Yes } \\
\text { Inspection of } \\
\text { documents in public } \\
\text { domain }\end{array}$ \\
\hline $\begin{array}{l}\text { Case B. } \\
\text { Location UK } \\
\text { Renovation project of leading } \\
\text { confectionery brand and NPD brand } \\
\text { extension. }\end{array}$ & $\begin{array}{l}\text { Global brand leader in food and beverage sector. } \\
276,000 \text { Employees } \\
500 \text { factories } \\
\text { Approx. Turnover } \$ 65 \text { billion } \\
\text { Innovation ethos: science based approach }\end{array}$ & $\begin{array}{l}\text { Head of Brand Marketing } \\
\text { Marketing Manager (6) } \\
\text { Brand Planning Manager (7) } \\
\text { Innovation Strategist (8) } \\
\text { Brand Strategy Consultant (9) } \\
\text { Innovation Consultant (10) } \\
\text { Market Research Manager (11) }\end{array}$ & $\begin{array}{l}40-45 \\
40-45 \\
30-35 \\
30-55 \\
40-45 \\
40-45 \\
30-35\end{array}$ & Yes & Yes \\
\hline $\begin{array}{l}\text { Case C. } \\
\text { Location UK: Global innovation unit. } \\
\text { Development of new to the market } \\
\text { alcoholic drinks }\end{array}$ & $\begin{array}{l}\text { Global brand leader in premium alcoholic drinks } \\
28,000 \text { Employees } \\
\text { Operates in } 180 \text { markets } \\
\text { Approx. Turnover } \$ 18.5 \mathrm{bn} \\
\text { Innovation ethos: responsible innovation and } \\
\text { marketing }\end{array}$ & $\begin{array}{l}\text { Consumer Planner (12) } \\
\text { Innovation Planner (13) } \\
\text { Marketing Manager (14) } \\
\text { Marketing Research Manager (15) } \\
\text { Market Research Consultant (16) }\end{array}$ & $\begin{array}{l}40-45 \\
35-40 \\
40-45 \\
30-35 \\
35-40\end{array}$ & Yes & Yes \\
\hline $\begin{array}{l}\text { Case D. } \\
\text { Location UK } \\
\text { Development of new to market and } \\
\text { to firm snack/confectionery product }\end{array}$ & $\begin{array}{l}\text { Global brand leader in food and beverage sector. } \\
276,000 \text { Employees } \\
500 \text { factories } \\
\text { Approx. Turnover } \$ 65 \text { billion } \\
\text { Innovation ethos: new market driven innovation hubs } \\
\text { supported by strong R\&D background. }\end{array}$ & $\begin{array}{l}\text { Innovation Manager (17) } \\
\text { Innovation Planner (18) } \\
\text { Innovation Project Manager (19) } \\
\text { Brand Manager (20) } \\
\text { Market Research Consultant (21) } \\
\text { Marketing/Innovation Consultant (22) }\end{array}$ & $\begin{array}{l}35-40 \\
30-35 \\
30-35 \\
30-35 \\
35-40 \\
40-45\end{array}$ & Yes & Yes \\
\hline
\end{tabular}


Figure 1. The Co-creation Process for NPD

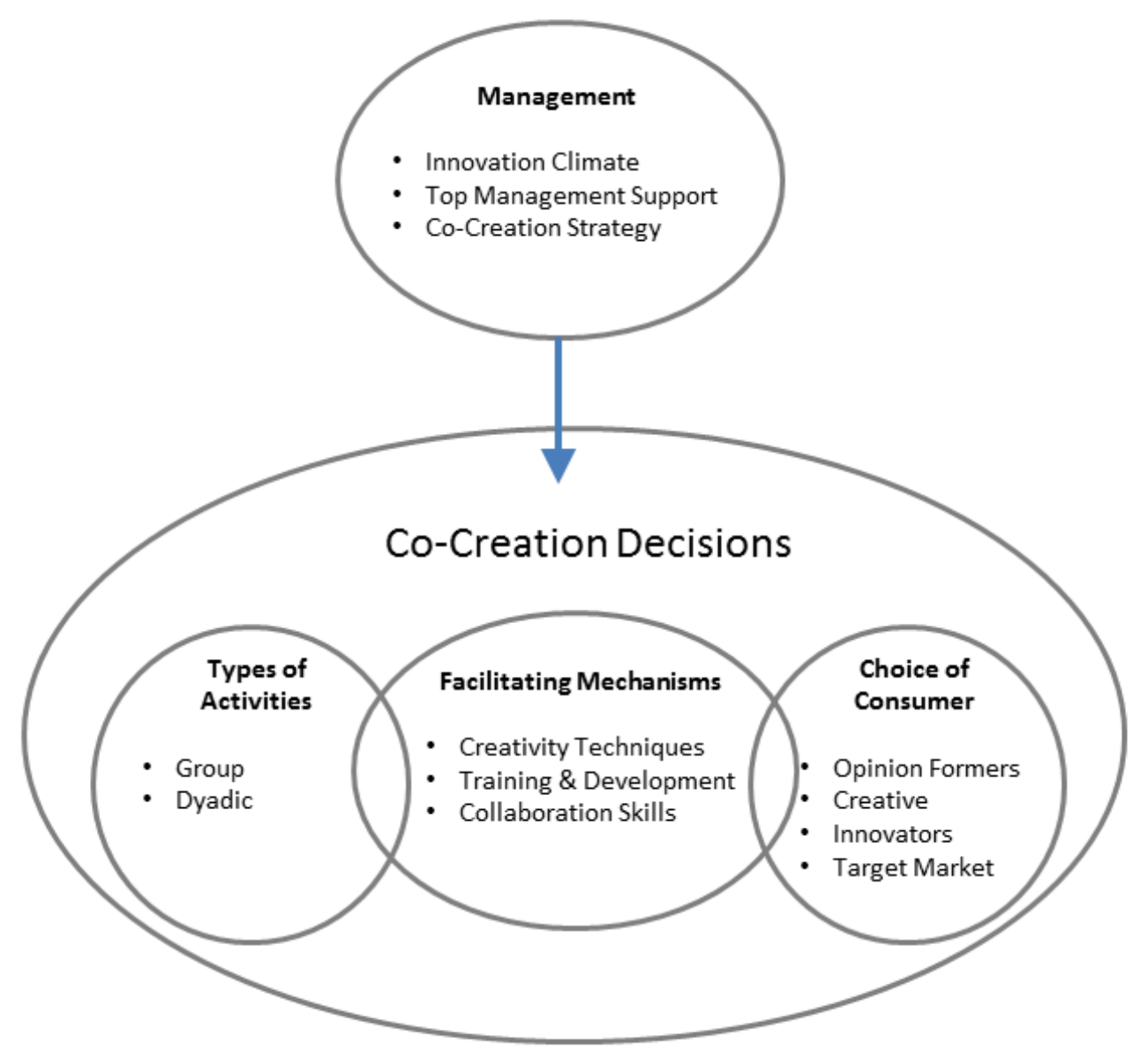

